\title{
Optimal Sizing of Battery Energy Storage System in Smart Microgrid with Air-conditioning Resources
}

\author{
Changhong Xie ${ }^{1}$, Dongxiao Wang ${ }^{1}$, Chun Sing Lai ${ }^{1,2}$, Runji Wu ${ }^{1}$, Jiachang Huang ${ }^{1}$, Loi Lei Lai ${ }^{1}$ \\ 1. School of Automation, Guangdong University of Technology, Guangzhou, China \\ 2. Brunel Institute of Power Systems, Brunel University London, London, United Kingdom
}

\begin{abstract}
In the microgrid with high photovoltaic (PV) penetration, optimal sizing of battery energy storage system (BESS) has been a heated research topic in recent years. In the meanwhile, the high energy consumption of air-conditioned households is attracting more and more attention currently. In this paper, an optimal sizing method of BESS is developed for a smart microgrid with $\mathbf{P V}$ systems and air-conditioning resources. The proposed model is divided into two layers. In the first layer, the initial size of BESS is determined with consideration of photovoltaic output power and thermal buffering characteristics of air-conditioned households. In the second layer, the optimal size of BESS is proposed to minimize the system overall cost including BESS construction investment and microgrid system operation cost. The model is solved by differential evolutionary algorithm and iterative algorithms. Case studies demonstrate the effectiveness of the proposed method.
\end{abstract}

Keywords-Air-conditioning Resources, Battery Energy Storage, Optimal Sizing, PV Arrays

\section{Nomenclature}

Abbreviatio
AC
BESS
BIPV
NZE
PV
SoC

Indices
$i$
$N$
$t$
$T$

\section{Parameters}

\begin{tabular}{|c|c|c|}
\hline$A_{P V}$ & Area of the $\mathrm{PV}\left[\mathrm{m}^{2}\right]$ & $T$ \\
\hline$A_{b e s s}^{E}$ & $\begin{array}{l}\text { The investment cost on BESS's capacity } \\
{[\$ / \mathrm{kWh}]}\end{array}$ & $T_{r}^{\min }$ \\
\hline$A_{\text {bess }}^{P}$ & $\begin{array}{l}\text { The investment cost on BESS's power } \\
{[\$ / \mathrm{kW}]}\end{array}$ & $T_{w}^{\min }$ \\
\hline$A_{\text {bess_M }}^{E}$ & $\begin{array}{l}\text { The maintenance cost on BESS's } \\
\text { capacity }[\$ / \mathrm{kWh}]\end{array}$ & $T_{r}^{\max }$ \\
\hline$A_{b e s S_{-} M}^{P}$ & $\begin{array}{l}\text { The maintenance cost on BESS's power } \\
{[\$ / \mathrm{kW}]}\end{array}$ & $T_{\max }^{\max }$ \\
\hline cop & Performance parameters & \\
\hline$C p_{a}$ & $\begin{array}{l}\text { The specific heat capacity of indoor air } \\
{\left[\mathrm{J} /\left(\mathrm{kg} \cdot{ }^{\circ} \mathrm{C}\right)\right]}\end{array}$ & $\begin{array}{l}\beta \\
\eta^{E s, d i s}\end{array}$ \\
\hline$C p_{w}$ & $\begin{array}{l}\text { The specific heat capacity of wall } \\
{\left[\mathrm{J} /\left(\mathrm{kg} \cdot{ }^{\circ} \mathrm{C}\right)\right]}\end{array}$ & $\eta^{E s, c h r}$ \\
\hline$I_{P V O}$ & $\begin{array}{l}\text { The average solar irradiation hourly at } \\
\text { nominal test condition }\left[\mathrm{kWh} / \mathrm{m}^{2}\right]\end{array}$ & $\eta_{P V}$ \\
\hline
\end{tabular}

$K_{c o e f}$
$M_{a}$
$M_{w}$
$M$
$P_{a c}$
$P_{b e s s, c h r}^{\max }$
$P_{b e s s, d i s}^{\max }$
$P_{b e s s, c h r}^{\min }$
$P_{b e s s, d i s}^{\min }$

$P_{g \_\max }$

$R_{e q}$

$R_{w r}$

Battery energy storage system

Building integrated photovoltaic

Net zero energy

Photovoltaic

State of charge

Index of air conditioner

The number of time intervals

Index of time interval

Index of the year

$R_{w a}$

$R_{B}$

So $C^{\max }$

SoC $C^{\min }$

$T_{\text {ref }}$

$T_{C O}$

$T_{A O}$

$T_{\text {life }}$

$T_{r}^{\min }$

$T_{w}^{\min }$

$T_{r}^{\max }$

$T_{w}^{\max }$

$\beta$

$\eta^{E s, d i s}$

$\eta^{E s, c h r}$

$\eta_{\text {ref }}$
The coefficient for calculating equivalent present value

Indoor air's mass [kg]

The mass of house walls [kg]

The total amount of air conditioners controlled by the aggregator

The rated power of $\mathrm{AC}$ [kW]

The upper limit value of charging power [kW]

The upper limit value of discharging power [kW]

The lower limit value of charging power [kW]

The lower limit value of discharging power $[\mathrm{kW}]$

The upper limit of the exchanged power for microgrid and distribution network [kW]

The equivalent thermal resistance for the household $\left[\left(\mathrm{m}^{2}{ }^{\circ} \mathrm{C}\right) / \mathrm{W}\right]$

The thermal resistance between outer wall surface and ambient air $\left[\left(\mathrm{m}^{2}{ }^{\circ} \mathrm{C}\right) / \mathrm{W}\right]$ The thermal resistance between inner wall surface and indoor air $\left[\left(\mathrm{m}^{2}{ }^{\circ} \mathrm{C}\right) / \mathrm{W}\right]$

The geometric factor

The upper limit value SoC [\%]

The lower limit value SoC [\%]

The standard test temperature $\left[{ }^{\circ} \mathrm{C}\right.$ ]

The cell temperatures at nominal test conditions $\left[{ }^{\circ} \mathrm{C}\right]$

The ambient temperature at nominal test conditions $\left[{ }^{\circ} \mathrm{C}\right]$

The working life of BESS [year]

The lower limit value of indoor temperature $\left[{ }^{\circ} \mathrm{C}\right]$

The lower limit value of wall temperature $\left[{ }^{\circ} \mathrm{C}\right.$ ]

The upper limit value of indoor temperature $\left[{ }^{\circ} \mathrm{C}\right]$

The upper limit value of wall temperature $\left[{ }^{\circ} \mathrm{C}\right.$ ]

The temperature coe cient

The discharge efficiency of BESS [\%]

The charging efficiency of BESS [\%]

Efficiency of the PV [\%]

Efficiency of the PV at standard test temperature [\%] 


$$
\begin{array}{ll}
\lambda & \text { The heat generation parameter }\left[\mathrm{W} / \mathrm{m}^{2}\right] \\
r & \text { The coefficient for discount }[\%] \\
e & \text { The energy escalation annually [\%/year] } \\
r^{\prime} & \text { The coefficient for equivalent discount } \\
\delta_{s_{-} d} & \text { The self-discharge rate of BESS [\%] } \\
\tau & \text { The time interval [min] }
\end{array}
$$

\section{Variables}

$\begin{array}{ll}C_{i n i} & \text { The minimum operation cost [\$] } \\ \min C & \text { The minimized system cost [\$] } \\ C_{b e s s} & \text { BESS's investment cost [\$] } \\ C_{O \& M} & \text { The microgrid system operation cost } \\ C_{M} & \text { including maintenance cost [\$] } \\ C_{o p} & \text { BESS's maintenance cost annually [\$] } \\ & \text { The operation cost daily in the microgrid }\end{array}$

$C_{b u y}(t) \quad$ microgrid to the distribution network at time $t[\$ / \mathrm{kWh}]$

The electricity sell price from the $C_{\text {sell }}(t) \quad$ microgrid to the distribution network at time $t[\$ / \mathrm{kWh}]$

$E_{\text {bess }}(t) \quad$ The capacity of BESS at time $t[\mathrm{kWh}]$

$E_{\text {bess,ini }}^{\text {rate }}$

$E_{\text {bess, rate }}$

$I_{B}(t)$

$I_{D}(t)$

$I_{P V}(t)$

$P_{a c_{-} i}(t)$

$P_{\text {bess,ini }}^{\text {rate }}$

$P_{\text {bess, rate }}$

$P_{g_{-} \text {buy }}(t)$

$P_{g \_s e l l}(t)$

$P_{\text {bess,chr }}(t)$

$P_{\text {bess,dis }}(t)$

$P_{\text {load }}(t)$

$P_{\text {uncontro_load }}(t)$ The uncontrollable load in the microgrid at time $t[\mathrm{~kW}]$

$P_{P V}(t)$

$S_{a c_{-} i}(t)$

$\operatorname{SoC}(t)$

$T_{r}(t)$

$T_{w}(t)$

$T_{a m b}(t)$

The initial rated capacity of BESS [kWh]

The rated capacity of BESS [kWh]

The global irradiation at time $t\left[\mathrm{~kW} \mathrm{~m} \mathrm{~m}^{2}\right]$

The diffuse irradiation at time $t\left[\mathrm{~kW} \mathrm{~m}^{2}\right]$

The solar irradiation at time $t\left[\mathrm{~kW} \mathrm{~m}{ }^{2}\right]$

The rated power of $\mathrm{i}$-th AC at time $t[\mathrm{~kW}]$

The initial rated power of BESS [kW]

The rated power of BESS [kW]

The amount of power purchasing from the microgrid to the distribution network at time $t[\mathrm{~kW}]$

The amount of power selling from the microgrid to the distribution network at time $t[\mathrm{~kW}]$

BESS's charging power at time $t[\mathrm{~kW}]$

BESS's discharging power at time $t[\mathrm{~kW}]$

The total load in the microgrid at time $t$ [kW]

The PV generation power at time $t[\mathrm{~kW})$

The operation status of $\mathrm{i}$-th $\mathrm{AC}$ at time $t$

BESS's SoC at time $t$ [\%]

The temperature value in the room at time $t\left[{ }^{\circ} \mathrm{C}\right]$

The temperature value in the wall at time $t\left[{ }^{\circ} \mathrm{C}\right]$

The ambient temperature values at time $t$ $\left[{ }^{\circ} \mathrm{C}\right]$

$$
\begin{aligned}
& \mu_{\text {bess,chr }}(t) \\
& \mu_{\text {bess,dis }}(t) \\
& x_{g_{-} \text {sell }}(t) \\
& x_{g_{-} \text {buy }}(t)
\end{aligned}
$$

BESS's charging status at time $t$

BESS's discharging status at time $t$

The status of purchasing electricity in microgrid at time $t$

The status of selling electricity in microgrid at time $t$

\section{INTRODUCTION}

As one of the main energy sources of the future smart microgrid, the photovoltaic (PV) penetration is increasing rapidly. The growth record of the installed capacity of renewable energy has reached more than $200 \mathrm{GW}$ in 2019 , which is mostly contributed by solar PV [1]. In order to meet the challenges of high PV penetration in a microgrid, it has been more and more important to be equipped with battery energy storage system (BESS) [2] [3].

Different research has put forward various optimal sizing methods of BESS. Reference [4] optimized cycle life of BESS to find the size of BESS without considering investment cost of BESS. However, the cost of BESS is still the key factor hindering its development [5] even though the cost of batteries is falling [6]. To minimize the total cost of BESS, the optimal size of BESS was evaluated based on frequency control in [7]. The authors in [8] developed an energy storage optimization configuration model considering various benefits to maximize user revenue within the lifecycle of BESS. In addition, the size of BESS was also determined to cope with the time-space imbalance of wind power generation and system revenue maximization considering the equivalent loss of BESS cycle life [9] and capacity fading of lithium ion battery [10]. In the meantime, the PV penetration rate increased by using BESS whose size was optimized [11]. Reference [12] proposed an optimal sizing strategy of BESS to increase PV penetration to $80 \%$ under voltage constraints. In [13], the authors determined battery capacity considering battery degradation cost in a $\mathrm{PV} /$ storage system. Furthermore, the building integrated photovoltaic (BIPV) system can nearly achieve net zero energy (NZE) [14] and lithium ion battery system is feasible in small-scale residential applications [15]. A NZE home equipped with rooftop PV was proposed in [16], and an optimal BESS size method was presented to minimize various costs. However, it did not take the maintenance cost of BESS into account.

The residential and office buildings have high energy consumption, which are mainly impacted by air-conditioning load [17][18]. In order to reduce the energy consumption, thermal buffering characteristics of air-conditioned buildings should be fully utilized. There have been some studies on this topic. For air-conditioning load in [19], the authors proposed a droop-based controller to participate in demand response to reduce building energy consumption. In [20], residential heating, ventilation, and air-conditioning model was established and combined with shared energy storage system to participate in demand response to save energy, but its thermal model was not accurate.

Reviewing the previous studies in detail, the authors find that the existing research on optimizing size of BESS mainly focus on minimizing the total cost of system by considering various factors such as capacity fading, uncertainties of renewable energy power generation and ancillary services etc. However, few of them consider about incorporating airconditioning resources in optimizing size of BESS. To close 
the research gap, this paper explores an optimal sizing method of BESS in a smart microgrid considering high penetration PV and a number of air-conditioned households which are modeled accurately. Including investment and maintenance cost of BESS and microgrid system operation cost, the total system cost is minimized through this method. The energy resources in smart microgrid are also managed optimally, which involve PV, BESS and air-conditioning load.

This paper is organized as follows. Section II provides the problem description. The various system component models are established in Section III. The proposed optimal sizing method of BESS is presented in Section IV. In Section V, the case study is introduced and the numerical simulations are analyzed. Finally, Section VI gives a conclusion.

\section{PROBLEM DESCRIPTION}

In a smart microgrid [21], it consists of renewable energy system (such as PV power generation system), energy storage system, load which is divided into controllable load and noncontrollable load, energy management system and various advanced communication facilities and sensors.

The simplified smart microgrid system structure is shown in Fig. 1. The PV system is the primary energy resource, which is green and sustainable to provide electricity for the microgrid. Furthermore, BESS provides energy buffering between generation and load. BESS is charged during high PV generation periods and discharged during high load demand periods. It should be noted that the PV system and BESS are owned by the microgrid system operator. As controllable loads, the air-conditioning (AC) loads are controlled by the aggregator to participate in the energy dispatching. In addition, the energy management system is used to optimize system energy management, and the microgrid is connected to power distribution network to achieve grid-connected and island operation. Note that the controllable loads in this paper refer to the $\mathrm{AC}$ load, while other loads are considered to be uncontrollable and constant loads.

In order to minimize investment cost of BESS, operation cost of the microgrid system, and optimize energy resource dispatching, an effective optimal sizing method of BESS should be developed. To fully utilize the thermal buffering characteristics of air-conditioned households, the airconditioned households should be modelled accurately and dispatched optimally.

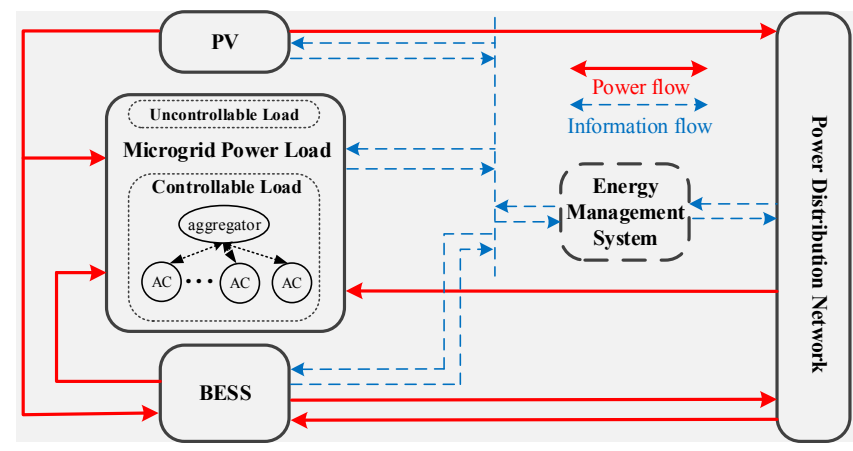

Fig. 1. Simplified smart microgrid system structure

\section{Microgrids COMPONENTS MODELLING}

In this section, including the air-conditioned household, BESS and PV system, the components modelling of microgrid are introduced.

\section{A. Air-conditioned Household Thermal Model}

The air-conditioned household has thermal buffering characteristic, i.e. the indoor temperature does not rise rapidly when the air conditioner is turned off, and vice versa. Therefore, to make the air-conditioned load to be controlled accurately by aggregator to meet thermal comfort of the users, it is vital to establish an accurate air-conditioned household model which can show the thermal process.

Many studies have provided various thermal models to describe the thermal process. In [20], the one-parameter model was adopted, but it ignored the effect of the house wall on the heat exchange process. In [22], a more accurate thermal model (two-parameter model) was formulated without considering the heat generation due to the activities of human and machine. Therefore, the heat generation parameter is added to the two-parameter model in this paper. A more accurate thermal process of household is described in Fig. 2. The airconditioned household mathematical thermal model is given as follows [22]:

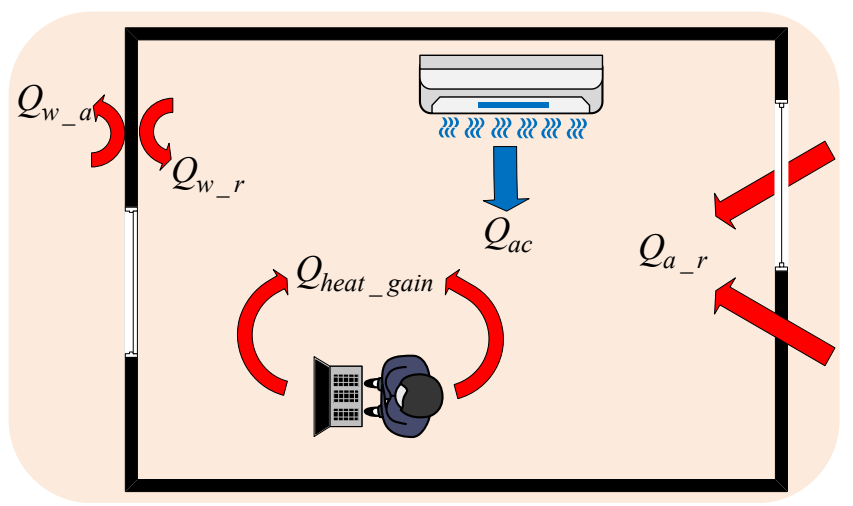

Fig. 2. Simplified thermal process of household

$$
T_{r}(t)=T_{r}(t-1)+\left[\begin{array}{c}
\frac{1}{M_{a} \cdot C p_{a}} \\
\frac{1}{M_{a} \cdot C p_{a}} \\
\frac{1}{M_{a} \cdot C p_{a}} \\
\frac{1}{M_{a} \cdot C p_{a}}
\end{array}\right]^{\mathrm{T}} \cdot\left[\begin{array}{c}
\frac{T_{a m b}(t-1)-T_{r}(t-1)}{R_{e q}} \\
\frac{T_{w}(t-1)-T_{r}(t-1)}{R_{w r}} \\
\lambda \\
-\operatorname{cop} \cdot P_{a c} \cdot S_{a c}(t-1)
\end{array}\right] \cdot \tau
$$

$$
t \in[1, N]
$$

$$
T_{w}(t)=T_{w}(t-1)+\left[\begin{array}{c}
\frac{1}{M_{w} \times C p_{w}} \\
\frac{1}{M_{w} \times C p_{w}}
\end{array}\right]^{\mathrm{T}} \cdot\left[\begin{array}{c}
\frac{T_{a m b}(t-1)-T_{w}(t-1)}{R_{w a}} \\
\frac{T_{r}(t-1)-T_{w}(t-1)}{R_{w r}}
\end{array}\right] \cdot \tau,
$$

$t \in[1, N]$

It should be noted that the air-conditioning state variables $S_{a c}$ is a binary variable (1 means the air conditioner is turned on, and 0 means it is turned off). In addition, a day is divided into $N$ time periods by time interval $\tau$, which is 15 minute in this paper. 


\section{B. Battery Energy Storage System}

Considering the state of charge (SoC), charge-discharge power and self-discharge for BESS [23], the model of BESS can be given as follows:

$$
\begin{gathered}
E_{\text {bess }}(t+1)=E_{\text {bess }}(t) \cdot\left(1-\delta_{s_{-} d}\right) \\
+P_{\text {bess }, \text { chr }}(t+1) \cdot \tau \cdot \eta^{E s, \text { chr }}-P_{\text {bess,dis }}(t+1) \cdot \tau / \eta^{E s, \text { dis }} \\
\operatorname{SoC}(t)=E_{\text {bess }}(t) / E_{\text {bess,rate }} \cdot 100 \% \\
E_{\text {bess }}(t)=E_{\text {bess,init }}, \quad \text { if } t=1 \\
P_{\text {bess,chr }}^{\min } \leq P_{\text {bess,chr }}(t) \leq P_{\text {bess, chr }}^{\max }, \forall t \in[1, N] \\
P_{\text {bess,dis }}^{\min } \leq P_{\text {bess,dis }}(t) \leq P_{\text {bess,dis }}^{\max }, \forall t \in[1, N] \\
\text { SoC } C^{\min } \leq \operatorname{SoC}(t) \leq \operatorname{SoC}{ }^{\max }
\end{gathered}
$$

\section{Photovoltaic System}

PV system is an important energy source in the microgrid, which generates power energy mainly depending on temperature and solar radiation. According to [24], the PV model is described as below:

$$
\begin{gathered}
P_{P V}(t)=A_{P V} \cdot I_{P V}(t) \cdot \eta_{P V} \\
I_{P V}(t)=\left(I_{B}(t)+I_{D}(t)\right) \cdot R_{B}+I_{D}(t) \\
\eta_{P V}=\eta_{r e f} \cdot\left\{1-\left[\begin{array}{c}
\frac{0.9 \cdot \beta \cdot I_{P V}(t)}{I_{P V O}} \\
-\frac{0.9 \cdot \beta \cdot I_{P V}(t)}{I_{P V O}}
\end{array}\right]^{\mathrm{T}} \cdot\left[\begin{array}{l}
T_{C O} \\
T_{A O}
\end{array}\right]-\left[\begin{array}{l}
\beta \\
\beta
\end{array}\right]^{\mathrm{T}} \cdot\left[\begin{array}{l}
T_{A}(t) \\
-T_{r e f}
\end{array}\right]\right\}
\end{gathered}
$$

Noted that $T_{r e f}, T_{C O}$ and $T_{A O}$ are generally $25^{\circ} \mathrm{C}, 45^{\circ} \mathrm{C}$ and $20^{\circ} \mathrm{C}$ respectively.

\section{Mathematical Formulation of The Proposed MODEL}

The optimal sizing method of BESS is proposed in this section, which is divided into two layers. The initial size of BESS is calculated in the first layer, and the optimal size of BESS is explored in the next layer. Simultaneously, minimizing the operation cost and saving energy, the energy resources are dispatched optimally.

\section{A. Initial Sizing Model of BESS in the First Layer}

To minimize operation cost in the smart microgrid considering high PV penetration and thermal buffering characteristics of air-conditioned households, the objective is provided as follows:

$$
C_{i n i}=\min \sum_{t=1}^{N}\left[P_{g_{-} b u y}(t) \cdot C_{b u y}(t)-P_{g_{-} \text {sell }}(t) \cdot C_{\text {sell }}(t)\right] \cdot \tau
$$

Equation (12) is further explained as below:

$$
\begin{aligned}
& \begin{cases}P_{g_{-} \text {sell }}(t)=P_{P V}(t)-P_{\text {load }}(t), & P_{P V}(t)>P_{\text {load }}(t) \\
P_{g_{-} \text {buy }}(t)=P_{\text {load }}(t)-P_{P V}(t), & P_{P V}(t)<P_{\text {load }}(t)\end{cases} \\
& P_{\text {load }}(t)=P_{\text {uncontro_load }}(t)+\sum_{i=1}^{M} P_{a c_{-} i}(t) \cdot S_{a c_{-} i}(t)
\end{aligned}
$$

In order to completely consume PV power generation onsite through BESS, the initial size of BESS can be determined as below:

$$
\begin{gathered}
P_{\text {bess, ini }}^{\text {rate }}=\max \left(P_{P V}(t)-P_{\text {load }}(t)\right) \\
E_{\text {bess, ini }}^{\text {rate }}=\frac{\sum_{t=1}^{N}\left[P_{P V}(t)-P_{\text {load }}(t)+\left|P_{P V}(t)-P_{\text {load }}(t)\right|\right] \cdot \tau}{2 \cdot \eta^{E s, c h r}}
\end{gathered}
$$

In addition, the following various constraints should be satisfied simultaneously.

\section{1) Power balance constraints:}

It is necessary for the microgrid to balance power consumption and power supply. Furthermore, the exchanged power with distribution network should meet the constraints due to the limitation of the facilities.

$$
\begin{aligned}
P_{\text {uncontro_load }}(t) & +\sum_{i=1}^{M}\left[P_{a c_{-} i}(t) \cdot S_{a c_{-} i}(t)\right]+P_{g_{-} \text {sell }}(t) \\
& =P_{P V}(t)+P_{g_{-} \text {buy }}(t) \\
& \left\{\begin{array}{l}
0 \leq P_{g_{-} \text {sell }}(t) \leq P_{g_{-} \max } \\
0 \leq P_{g_{-} \text {buy }}(t) \leq P_{g_{-} \max }
\end{array}\right.
\end{aligned}
$$

2) Air-conditioned household thermal constraints:

To meet thermal comfort for the user, the following constraints need to be satisfied:

$$
\begin{aligned}
& T_{r}^{\min } \leq T_{r}(t) \leq T_{r}^{\max } \\
& T_{w}^{\min } \leq T_{w}(t) \leq T_{w}^{\max }
\end{aligned}
$$

Noted that the controllable range of temperature is determined by the user.

\section{B. Optimal Sizing Model of BESS in the Second Layer}

After calculating the initial size of BESS, it is important to find the optimal BESS's size for minimizing total system cost. Therefore, considering investment and maintenance cost of 
BESS and operation cost of the microgrid, the objective is proposed as below:

$$
\min C=\min \left(C_{\text {bess }}+C_{O \& M}\right)
$$

The definitions of $C_{b e s s}$ and $C_{O \& M}$ are further described as below:

$$
\begin{gathered}
C_{\text {bess }}=A_{\text {bess }}^{E} \cdot E_{\text {bess, rate }}+A_{\text {bess }}^{P} \cdot P_{\text {bess, rate }} \\
C_{O \& M}=\min \sum_{T=1}^{T_{\text {life }}}\left[\frac{C_{o p} \cdot 365+C_{M}}{K_{\text {coef }}}\right]
\end{gathered}
$$

Specially, $C_{o p}, C_{M}$ and $K_{c o e f}$ are defined as:

$$
\begin{gathered}
C_{\text {op }}=\min \sum_{t=1}^{N}\left[P_{g_{-} \text {buy }}(t) \cdot C_{\text {buy }}(t)-P_{g_{-} \text {sell }}(t) \cdot C_{\text {sell }}(t)\right] \cdot \tau \\
C_{M}=A_{\text {bess_ }}^{E} M \cdot E_{\text {bess,rate }}+A_{\text {bess_ }}^{P} \cdot P_{\text {bess, rate }} \\
K_{\text {coef }}=\frac{r^{\prime}\left(1+r^{\prime}\right)^{T}}{\left(1+r^{\prime}\right)^{T}-1} \\
r^{\prime}=\frac{r-e}{1+e}
\end{gathered}
$$

The various constraints are as follows:

1) Power balance constraints:

$$
\begin{aligned}
& P_{\text {uncontro_load }}(t)+\left[\begin{array}{c}
P_{\text {bess,chr }}(t) \\
P_{g_{-} \text {sell }}(t)
\end{array}\right]^{\mathrm{T}} \cdot\left[\begin{array}{c}
\mu_{\text {bess,chr }}(t) \\
x_{g_{-} \text {sell }}(t)
\end{array}\right] \\
& +\sum_{i=1}^{M}\left[P_{a c_{-} i}(t) \cdot S_{a c_{-} i}(t)\right]=P_{P V}(t)+\left[\begin{array}{c}
P_{\text {bess, }, d i s}(t) \\
P_{g_{-} b u y}(t)
\end{array}\right]^{\mathrm{T}} \cdot\left[\begin{array}{c}
\mu_{\text {bess, dis }}(t) \\
x_{g_{-} b u y}(t)
\end{array}\right] \\
& \left\{\begin{array}{l}
0 \leq P_{g_{-} \text {sell }}(t) \leq P_{g_{-} \max } \\
0 \leq P_{g_{-} \text {buy }}(t) \leq P_{g_{-} \max }
\end{array}\right. \\
& \left\{\begin{array}{c}
\mu_{\text {bess }, \text { chr }}(t)+\mu_{\text {bess,dis }}(t) \leq 1 \\
\mu_{\text {bess,chr }}(t), \quad \mu_{\text {bess,dis }}(t) \in\{0,1\}
\end{array}\right. \\
& \left\{\begin{array}{c}
x_{g_{-} \text {sell }}(t)+x_{g_{-} \text {buy }}(t) \leq 1 \\
x_{g_{-} \text {sell }}(t), x_{g_{-} \text {buy }}(t) \in\{0,1\}
\end{array}\right.
\end{aligned}
$$

This means that charging and discharging of BESS cannot be performed simultaneously in (31). Equation (32) gives the purchase and sale of electricity between the microgrid and the distribution network that cannot be carried out simultaneously.

2) Air-conditioned household thermal constraints:

The thermal constraints of air-conditioned household are shown in (19) - (21).
3) Battery energy storage system constraints:

BESS constraints should be met to ensure safe and stable operation, as shown in (5) - (8).

The initial size can be calculated through solving the initial sizing model of BESS in the first layer. Then, combining iterative search algorithm and differential evolution algorithm, the optimal size of BESS can be found. It should be noted that $E_{\text {bess,rate }}$ and $P_{\text {bess, rate }}$ are variables that change in each iteration.

\section{CAse Studies}

The method in this paper is tested in the microgrid system shown in Fig. 3. The models have been simulated with MATLAB software.

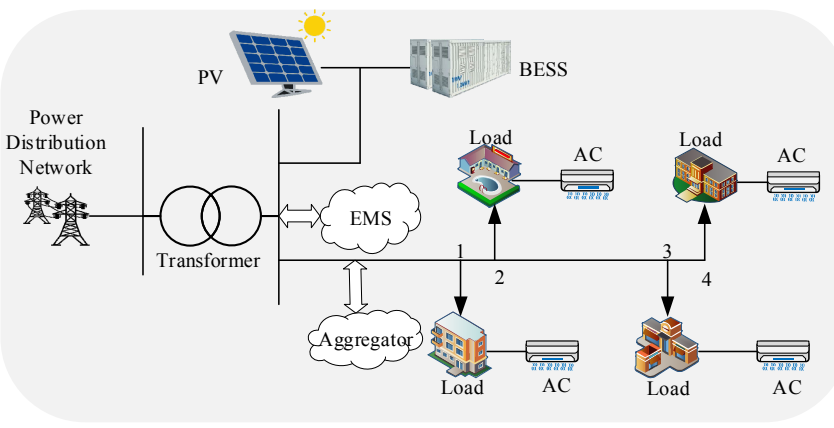

Fig. 3. The microgrid system

According to the solar irradiation and ambient temperature which are collected in Guangzhou City, Guangdong Province for a certain typical day, the PV power generation is simulated by (9) - (11). The load and PV curves are shown in Fig. 4. The electricity price is given in Fig. 5.

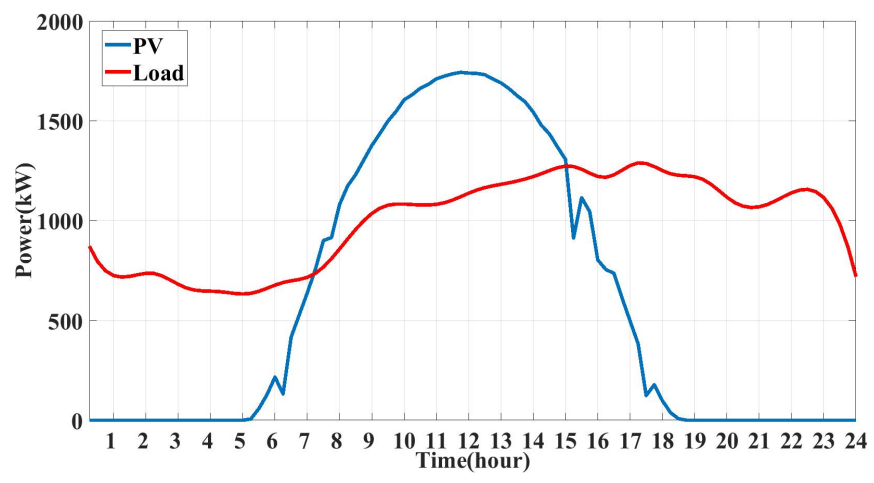

Fig. 4. The load and PV curves

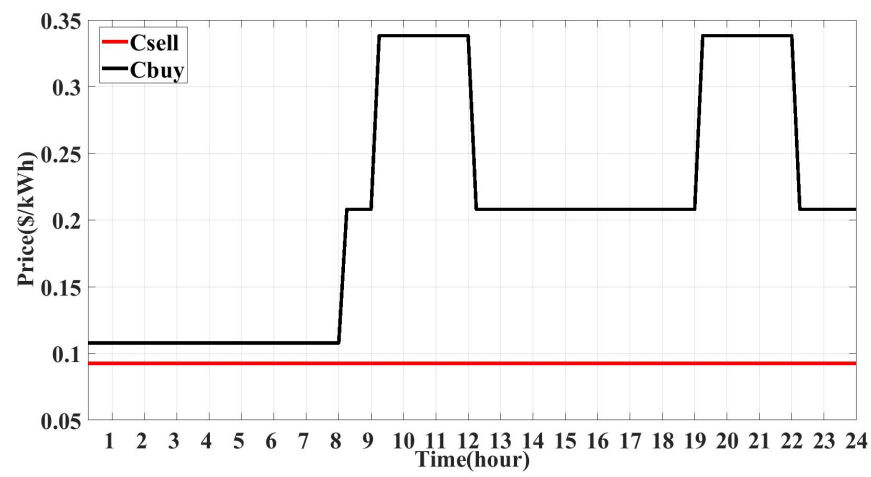

Fig. 5. The electricity price 
In this paper, assuming that 150 air-conditioned households are controlled by an aggregator, Monte Carlo simulation is used to generate the air-conditioned households scenarios whose parameters range is given in Table I below:

TABLE I. PARAMETERS OF AIR-CONDITIONED HOUSEHOLD

\begin{tabular}{c|c|c|c}
\hline $\begin{array}{c}\text { Building } \\
\text { Length (m) }\end{array}$ & $\begin{array}{c}\text { Building Width } \\
(\mathbf{m})\end{array}$ & $\begin{array}{c}\text { Building } \\
\text { Height (m) }\end{array}$ & $\begin{array}{c}\text { Wall Width } \\
(\mathbf{m})\end{array}$ \\
\hline $8-22$ & $8-15$ & $3-9$ & $0.2-0.4$ \\
\hline $\begin{array}{c}\text { No. of } \\
\text { Windows }\end{array}$ & $\begin{array}{c}\text { Comfort } \\
\text { Temperature }\left({ }^{\circ} \mathbf{C}\right)\end{array}$ & $\begin{array}{c}\text { Air Conditioners Rated } \\
\text { Power }(\mathbf{k W})\end{array}$ \\
\hline $3-8$ & $23-27$ & \multicolumn{2}{|c}{$3-7$} \\
\hline
\end{tabular}

According to Reference [23], the parameters of BESS are given in Table II below:

TABLE II. PARAMETERS OF BESS

\begin{tabular}{|c|c|c|c|}
\hline $\begin{array}{l}\text { Type of } \\
\text { battery }\end{array}$ & $\begin{array}{c}A_{\text {bess }}^{E} \\
(\$ / \mathbf{k W h})\end{array}$ & $\begin{array}{c}A_{\text {bess }}^{P} \\
(\$ / \mathbf{k W})\end{array}$ & $\begin{array}{c}A_{\text {bess_M }}^{E} \\
(\$ /(\mathbf{k W h} \cdot \text { year }))\end{array}$ \\
\hline $\begin{array}{c}\text { Lithium ion } \\
\text { battery }\end{array}$ & 250 & 300 & 7.5 \\
\hline $\begin{array}{c}A_{\text {bess_M }}^{P} \\
(\$ /(\mathbf{k W} \cdot \text { year }))\end{array}$ & $\begin{array}{c}T_{\text {life }} \\
\text { (year) }\end{array}$ & $\begin{array}{c}S o C_{\min } \\
/ \operatorname{SoC}_{\max } \\
(\%)\end{array}$ & $\begin{array}{c}\delta_{s_{-} d} \\
(\% / \text { day })\end{array}$ \\
\hline 6 & 8 & $20 / 80$ & 0.1 \\
\hline \multicolumn{2}{|c|}{$r(\%)$} & \multicolumn{2}{|c|}{$e(\% /$ year $)$} \\
\hline \multicolumn{2}{|c|}{6} & \multicolumn{2}{|c|}{3.5} \\
\hline
\end{tabular}

It can be seen that the relationship between size of BESS and total microgrid system cost of the microgrid in Fig. 6. As the BESS size increases, the BESS investment cost increases but the total cost of microgrid decreases to saturation. The reason is that BESS participates in electricity price arbitrage and microgrid auxiliary service. Therefore, the optimal size of BESS can be determined by finding the minimum total microgrid system cost of the microgrid and in this case, they are $1406.3 \mathrm{~kW}$ and $6904.7 \mathrm{kWh}$ as shown in Fig. 6.

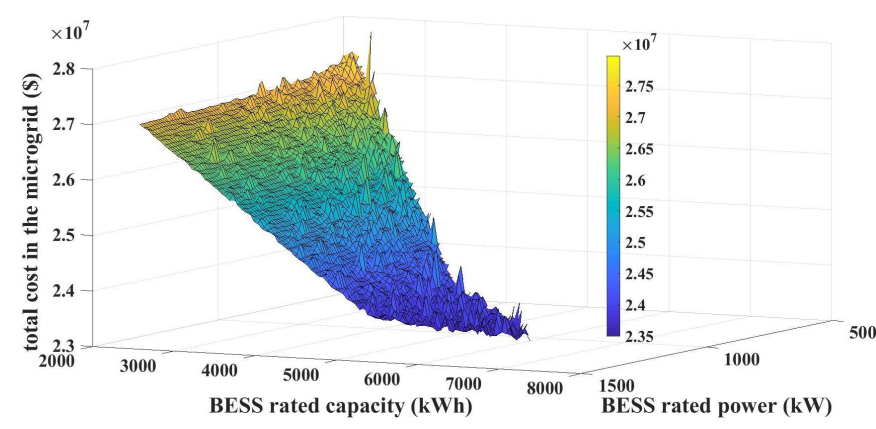

Fig. 6. The relationship between BESS size and microgrid system cost

The air-conditioned households are aggregated and controlled by the aggregator to minimize air-conditioning power consumption. To verify the validity of the model, the different modes of air conditioners are compared as shown in Fig. 7, which are divided into control mode and uncontrol mode. Noted that the blue line, red line and black line denote ambient temperature, indoor temperature and operation status of air conditioner respectively. It can be seen that the power consumption of air conditioner in control mode is less than that in uncontrol mode.
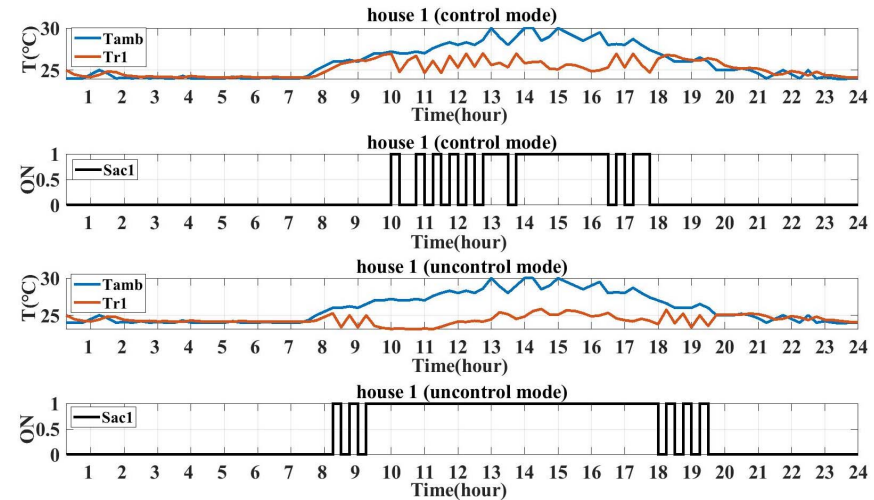

Fig. 7. Air-conditioned household with control and without control

Fig. 8 reports the BESS operation status including SoC and charging/discharging power of BESS in a day. It is obvious that with the constraints, BESS charging only occurs during periods of low prices or periods where there is surplus PV generation power. In addition, BESS is mainly discharged when the electricity price is at high level and the PV generation power is insufficient.

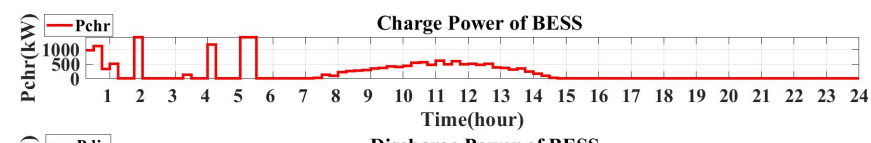
王

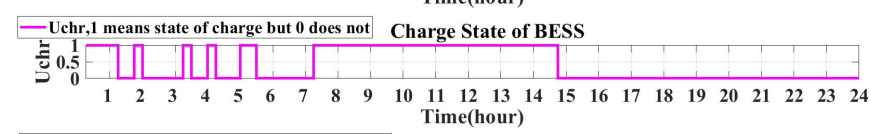

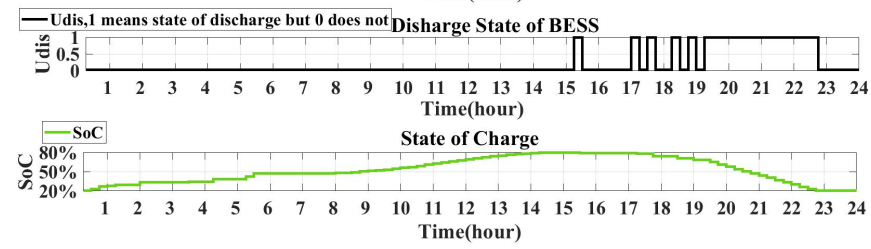

Fig. 8. BESS operation status

Fig. 9 indicates the power exchange between microgrid and distribution network. The yellow line and bottle-green line are power purchasing from the distribution network and the corresponding status ( 1 is power purchasing, 0 is not). It can be observed that the PV power generation is completely consumed locally, and there is no electricity transaction between the microgrid and the distribution network during peak electricity prices. In addition, the electricity sold by the microgrid to the distribution network is zero, which is due to the electricity selling price is very low, and the surplus PV generation power is consumed locally with BESS.

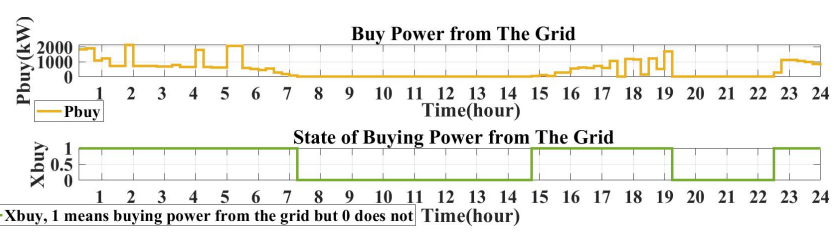

Fig. 9. Power exchange between microgrid and distribution network

\section{CONCLUSION}

In this paper, an optimal sizing method of BESS is proposed in smart microgrid which includes high PV penetration and air-conditioning resources. Composed by initial sizing model of BESS and optimal sizing model of 
BESS, there are two layers in the proposed model to minimize total system cost. According to the simulation results, the optimal size of BESS can be obtained while minimizing the total system cost. In addition, the more accurate twoparameter air-conditioners can be controlled by the aggregator to reduce energy consumption. The energy resources in the microgrid are optimally scheduled to cope with high penetration of $\mathrm{PV}$, reduce peak demand, and lower the system cost.

\section{ACKNOWLEDGMENTS}

This work is sponsored in part by the Guangdong Foshan Power Construction Corporation Group Co., Ltd; in part by the Department of Finance and Education of Guangdong Province 2016 [202]: Key Discipline Construction Program, China; in part by the Education Department of Guangdong Province: New and Integrated Energy System Theory and Technology Research Group [Project Number 2016KCXTD022]; in part by the National Natural Science Foundation of China under Grant 51907031 and in part by the Brunel University London BRIEF Funding.

\section{REFERENCES}

[1] Renewables 2020 Global Status Report - REN21, [Online]: https://www.ren21.net/gsr-2020/chapters/chapter_01/chapter_01/ (Accessed 06/07/2020)

[2] S. Comello and S. Reichelstein, "The emergence of cost effective battery storage," Nature Communications, vol. 10, pp. 1-9, May 2019.

[3] D. Wang, K. Meng, F. Luo, C. Coates, X. Gao and Z. Y. Dong, "Coordinated dispatch of networked energy storage systems for loading management in active distribution networks," IET Renewable Power Generation, vol. 10, no. 9, pp. 1374-1381, October 2016.

[4] V. Rasouli and R. Hemmati, "Net zero energy home including photovoltaic solar cells, wind turbines, battery energy storage systems and hydrogen vehicles," 2017 International Conference in Energy and Sustainability in Small Developing Economies (ES2DE), Funchal, 2017, pp. 1-5, July 2017.

[5] L. A. Wong, V. K. Ramachandaramurthy, P. Taylor, J. B. Ekanayake, S. L. Walker and S. Padmanaban, "Review on the optimal placement, sizing and control of an energy storage system in the distribution network," Journal of Energy Storage, vol. 21, pp. 489-504, February 2019.

[6] B. Nykvist and M. Nilsson, "Rapidly falling costs of battery packs for electric vehicles," Nature Climate Change, vol. 5, pp. 329-332, March 2015.

[7] T. Kerdphol, K. Fuji, Y. Mitani, M. Watanabe and Y. Qudaih, "Optimization of a battery energy storage system using particle swarm optimization for stand-alone microgrids," International Journal of Electrical Power \& Energy Systems, vol. 81, pp. 32-39, October 2016.

[8] L. Chen, T. Wu and X. Xu, "Optimal configuration of different energy storage batteries for providing auxiliary service and economic revenue," Applied Sciences, vol. 8, pp. 1-17, December 2018.

[9] X. Jiang, G. Nan, H. Liu, Z. Guo, Q. Zeng and Y. Jin, "Optimization of battery Energy storage system capacity for wind farm with considering auxiliary services compensation," Applied Sciences, vol. 8, pp. 1-17, October 2018.

[10] Y. Liu, X. Wu, J. Du, Z. Song and G. Wu, "Optimal sizing of a windenergy storage system considering battery life," Renewable Energy, vol. 147, pp. 2470-2483, September 2019.

[11] C. S. Lai and M. D. McCulloch, "Levelized cost of electricity for solar photovoltaic and electrical energy storage," Applied Energy, vol. 190, pp. 191-203, 2017.

[12] L. Bitencourt, A. M. Schetinger, B. S. M. C. Borba, D. H. N. Dias, R. S. Maciel and B. H. Dias, "Maximum PV penetration under voltage constraints considering optimal sizing of BESS on Brazilian secondary distribution network," IEEE Latin America Transactions, vol. 14, no. 9, pp. 4063-4069, September 2016.

[13] M. Gitizadeh and H. Fakharzadegan, "Battery capacity determination with respect to optimized energy dispatch schedule in grid-connected photovoltaic (PV) systems," Energy, vol. 65, pp. 665-674, February 2014.

[14] P. Sharma, M. Kolhe and A. Sharma, "Economic performance assessment of building integrated photovoltaic system with battery energy storage under grid constraints," Renewable Energy, vol. 145, pp. 1901-1909, January 2020.

[15] P. Nikolaidis and A. Poullikkas, "Cost metrics of electrical energy storage technologies in potential power system operations," Sustainable Energy Technologies and Assessments, vol. 25, pp. 43-59, February 2018.

[16] V. Sharma, M. H. Haque and S. M. Aziz, "Energy cost minimization for net zero energy homes through optimal sizing of battery storage system," Renewable Energy, vol. 141, pp. 278-286, October 2019.

[17] H. Ma, N. Du, S. Yu, W. Lu, Z. Zhang, N. Deng and C. Li, "Analysis of typical public building energy consumption in northern China," Energy and Buildings, vol. 136, pp. 139-150, February 2017.

[18] D. Wang, K. Meng, X. Gao, C. Coates and Z. Dong, "Optimal airconditioning load control in distribution network with intermittent renewables," Journal of Modern Power Systems and Clean Energy, vol. 5, no. 1, pp. 55-65, January 2017.

[19] S. k. Gupta, T. Ghose and K. Chatterjee, "Droop Based Dynamic Demand Response Controller for HVAC Load," 2018 20th National Power Systems Conference (NPSC), Tiruchirappalli, India, pp. 1-6, December 2018.

[20] A. Taşcıkaraoğlu, N. G. Paterakis, O. Erdinç and J. P. S. Catalão, "Combining the flexibility from shared energy storage systems and DLC-Based demand response of HVAC units for distribution system operation enhancement," IEEE Transactions on Sustainable Energy, vol. 10, no. 1, pp. 137-148, January 2019.

[21] G. K. Venayagamoorthy, R. K. Sharma, P. K. Gautam and A. Ahmadi, "Dynamic energy management system for a smart microgrid," IEEE Transactions on Neural Networks and Learning Systems, vol. 27, no. 8, pp. 1643-1656, August 2016.

[22] D. Wang, R. Wu, X. Li, C.S. Lai, X. Wu, J. Wei, Y. Xu, W. Wu and L.L. Lai, "Two-stage optimal scheduling of air conditioning resources with high photovoltaic penetrations," Journal of Cleaner Production, vol. 241, pp. 118407, December 2019.

[23] D. L. Rodrigues, X. Ye, X. Xia and B. Zhu, "Battery energy storage sizing optimisation for different ownership structures in a peer-to-peer energy sharing community," Applied Energy, vol. 262, pp. 114498, March 2020.

[24] H. Tazvinga, X. Xia and J. Zhang, "Minimum cost solution of photovoltaic-diesel-battery hybrid power systems for remote consumers," Solar Energy, vol. 96, pp. 292-299, October 2013. 